\title{
Giant Epidermal Inclusion Cyst of Floor of Mouth
}

\author{
${ }^{1}$ Varun Rai, ${ }^{2}$ Nikhil Arora, ${ }^{3}$ Vikas Malhotra, ${ }^{4} \mathrm{JC}$ Passey
}

\section{ABSTRACT}

Epidermal inclusion cysts form a part of a spectrum of teratomas, and the floor of the mouth is one of the most common cervical locations. What makes our case stand out is the size of the tumor and our approach of tackling it with a minimally invasive incision.

Keywords: Epidermal inclusion cyst, Floor of mouth, S 100.

How to cite this article: Rai V, Arora N, Malhotra V, Passey JC. Giant Epidermal Inclusion Cyst of Floor of Mouth. Int J Otorhinolaryngol Clin 2014;6(3):101-102.

\section{Source of support: Nil}

\section{Conflict of interest: None}

\section{CASE REPORT}

A 26-year-old male presented to the Outpatient Department (OPD) of ENT at Lok Nayak Hospital, New Delhi, with complaints of swelling in floor of mouth extending to the midline of neck since 4 months, which was gradually progressive in nature. He also had complaints of change in voice and difficulty in swallowing since 2 months. On examination, there was a $5 \times 6 \mathrm{~cm}$ swelling in floor of mouth, cystic, firm, nontender, fluctuant and with negative transillumination test. There were no palpable neck nodes on presentation.

On ultrasonography (USG) of neck, the swelling was found to be $10 \times 8 \mathrm{~cm}$, well circumscribed, encapsulated cystic lesion extending from floor of mouth to the hyoid bone, between the anterior bellies of digastric muscle. The differential diagnosis of ranula, dermoid cyst and epidermal cyst were considered. Fine needle aspiration cytology (FNAC) yielded cheesy material, which diagnosed the swelling as epidermal inclusion cyst.

The patient was taken up for surgical excision under general anesthesia, and an intraoral midline incision in the anteroposterior direction (Fig. 1) was given and the cyst excised in toto (Figs 2A and B) after mobilization from surrounding adhesions and separation from tissues including muscles of floor of mouth. The lesion had a thin capsule with cheesy keratinous material

\footnotetext{
${ }^{1,2}$ Senior Resident, ${ }^{3,4}$ Professor

${ }^{1-4}$ Department of ENT, Lok Nayak Hospital, New Delhi, India
}

Corresponding Author: Varun Rai, Senior Resident, Department of ENT, H-465, New Rajinder Nagar, New Delhi-110060, India Phone: 011-28745642, e-mail: varun rai@me.com

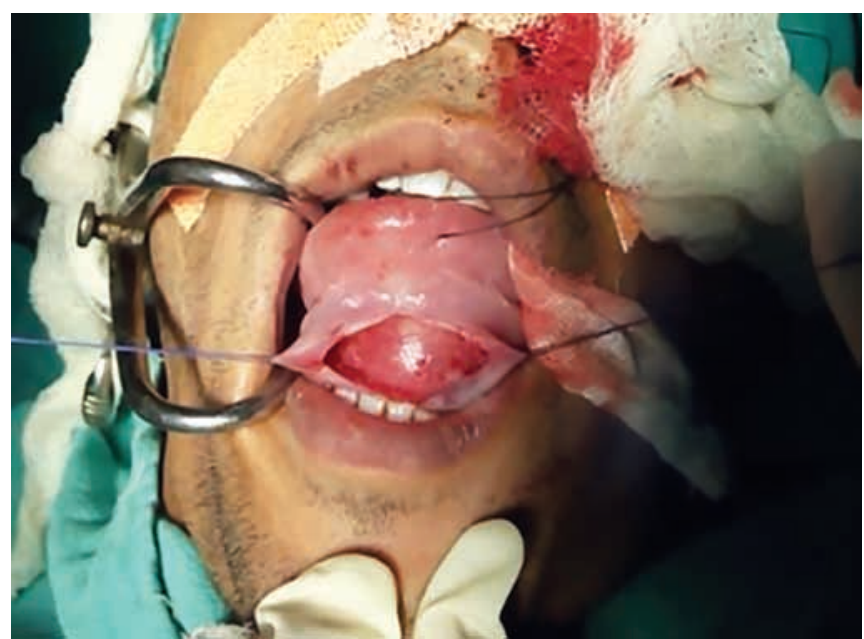

Fig. 1: Vertical midline anteroposterior incision given to expose the cyst
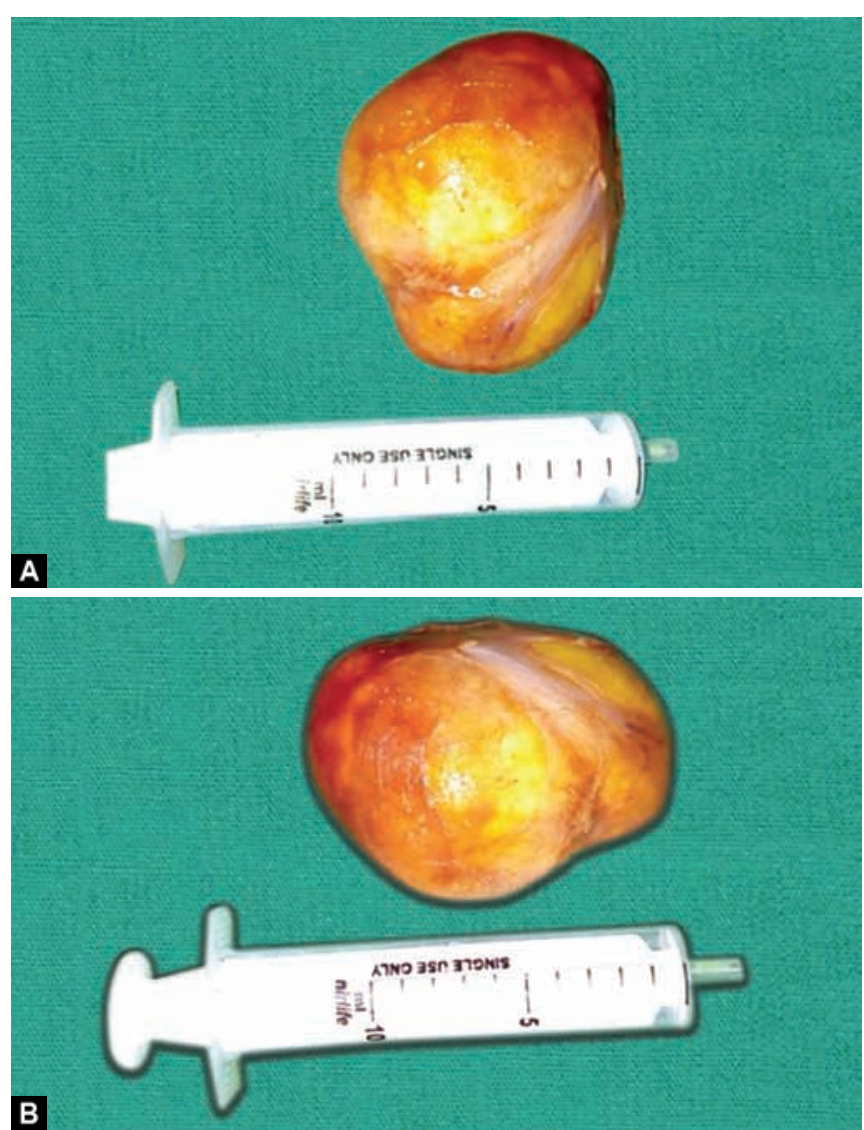

Figs 2A and B: Cyst excised in toto

within. The postoperative period was uneventful. The final histopathologic report confirmed the diagnosis of epidermal inclusion cyst with features of unilocular cyst with flattened epithelial lining and acellular keratin debris forming the matrix of the cyst (Fig. 3). 


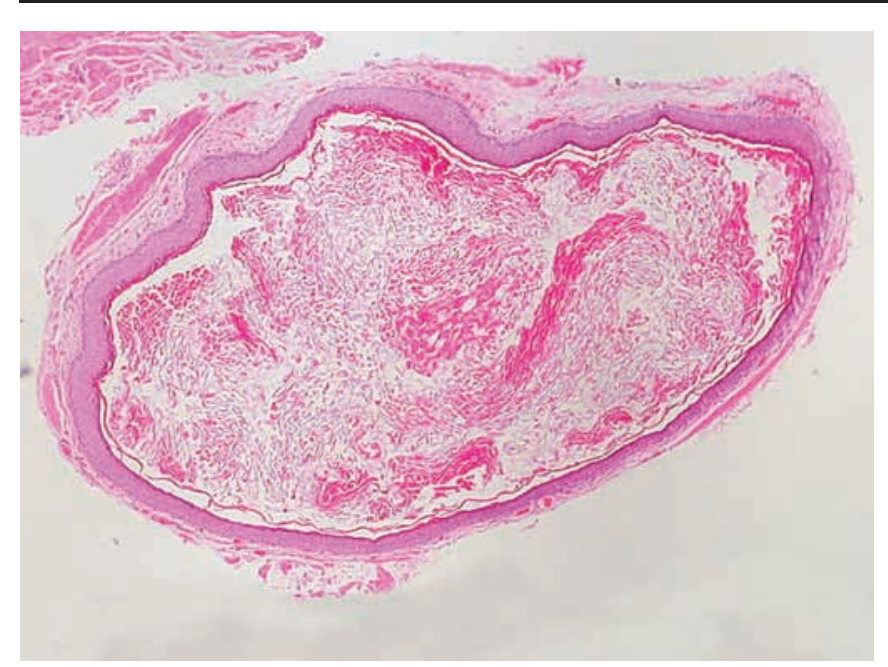

Fig. 3: Histopathologic picture showing features of epidermal inclusion cyst

\section{DISCUSSION}

The differential diagnosis of swellings in the floor of mouth range from simple ranulas, infectious causes, lithiasis, dermoid cysts, epidermal inclusion cysts to teratomas and malignancies. ${ }^{1}$ The spectrum of teratomas includes: true dermoid cysts, epidermal cysts and teratomas. ${ }^{4}$ The etiology of both the dermoid and the epidermal cysts is the failure of the surface ectoderm in separating from the underlying structures, resulting in the sequestration and the implantation of the surface ectoderm. There is no gender predilection for epidermal cysts. The most common cervical location of the dermoid and the epidermal cysts is the floor of the mouth. ${ }^{7}$ They present as soft, mobile and slow growing masses and they are unattached to the overlying skin. 8,9 They have no intimate association with the hyoid bone; hence, they do not tend to move on the protrusion of the tongue. Ultrasonographically, they have solid and cystic structures within a heterogeneous mass, rarely with calcifications. On computed tomography (CT) scans, they are found to be moderately thin walled, unilocular masses which are filled with a homogeneous, hypoattenuating $(0-18 \mathrm{HU})$ fluid material, with multiple hypoattenuating fat nodules, giving a 'sack-of-marbles' appearance, which is virtually pathognomonic for the dermoid cysts in this location. 2,3
The treatment involves complete surgical excision without rupturing the cyst, as the contents may act as irritants to the surrounding fibrovascular tissue, producing postoperative inflammation. Traditionally, intraoral approaches have been used for smaller cysts confined to the oral cavity while larger cysts extending to submental triangle ${ }^{5,6}$ require a transcervical approach. Our case differs in the fact that we delivered the entire cyst through a minimally invasive intraoral route. Recurrences are rare for this lesion.

\section{CONCLUSION}

This is a rare case of epidermal inclusion cyst in the floor of mouth extending to the submental triangle. Ultrasonography and FNAC are usually diagnostic for this condition. In cases of doubt, a CT scan may be required. We did not get a CT done for our case due to adequate information provided on USG. Surgical excision is the treatment of choice and recurrences are rare.

\section{REFERENCES}

1. Antoni AA, Van De Mark TB, Weinberg S. Epidermoid inclusion cyst of the floor of mouth: a case report. J Can Dent Assoc 1966 Nov;32(11):659-660.

2. Maydew M, Fujinaga K. Epidermal inclusion cyst presenting as a large submental mass following gastric bypass surgery. Int J Radiol 2006;6(1).

3. Coit W, et al. Ranulas and their mimics: CT evaluation. Radiology 1987;163:211-216.

4. Dimov Zh, et al. Dermoid, epidermoid and teratomas cysts of the tongue and oral cavity floor. Khirurgiia (Sofiia) 2000; 56(2):30-32.

5. Calderon S, Kaplan I. Concomitant sublingual and submental epidermoid cysts: a case report. J Oral Maxillofac Surg 1993; 51:790-792.

6. Zachariades N, Skoura-Kafoussia C. A life threatening epidermoid cyst of the floor of the mouth: report of a case. J Oral Maxillofac Surg 1990,48:400

7. Koca H, Seckin T, Sipahi A, Kazanc A. Epidermoid cyst in the floor of the mouth: report of a case. Quintessence Int 2007; 38:473-477.

8. Yilmaz I, Yilmazer C, Yavuz H, Bal N, Ozluoglu LN. Giant sublingual epidermoid cyst: a report of two cases. J Laryngol Otol 2006;120:E19.

9. Lowry RE, Tempero RM, Davis LF. Epidermoid cyst of the floor of the mouth. J Oral Surg 1979;37:271. 